\title{
Differential Expression of the mRNA for the Vanilloid Receptor Subtype 1 in Cells of the Adult Rat Dorsal Root and Nodose Ganglia and Its Downregulation by Axotomy
}

\author{
Gregory J. Michael and John V. Priestley \\ Neuroscience Section, Division of Biomedical Sciences, Queen Mary and Westfield College, London E1 4NS, \\ United Kingdom
}

Sensitivity to the pungent vanilloid, capsaicin, defines a subpopulation of primary sensory neurons that are mainly polymodal nociceptors. The recently cloned vanilloid receptor subtype 1 (VR1) is activated by capsaicin and noxious heat. Using combined in situ hybridization and histochemical methods, we have characterized in sensory ganglia the expression of VR1 mRNA. We show that this receptor is almost exclusively expressed by neurofilament-negative small- and medium-sized dorsal root ganglion cells. Within this population, VR1 mRNA is detected at widely varying levels in both the NGF receptor (trkA)-positive, peptide-producing cells that elicit neurogenic inflammation and the functionally less characterized glial cell line-derived neurotrophic factor-responsive cells that bind lectin Griffonia simplicifolia isolectin B4 (IB4). Cells without detectable levels of VR1 mRNA are found in both classes. A subpopulation of the IB4-binding cells that produce somatostatin has relatively low levels of VR1 mRNA. A previously uncharacterized population of very small cells that express the receptor tyrosine kinase (RET) and that do not label for trkA or IB4-binding has the highest relative levels of VR1 mRNA. The majority of small visceral sensory neurons of the nodose ganglion also express VR1 mRNA, in conjunction with the BDNF receptor trkB but not trkA. Axotomy results in the downregulation of VR1 mRNA in dorsal root ganglion cells.

Our data emphasize the heterogeneity of VR1 mRNA expression by subclasses of small sensory neurons, and this may result in their differential sensitivity to chemical and noxious heat stimuli. Our results also indicate that peripherally derived trophic factors may regulate levels of VR1 mRNA.

Key words: axotomy; capsaicin; immunocytochemistry; in situ hybridization; nociception; sensory neuron subpopulations; vanilloid receptor; VR1
Capsaicin, the main "hot" ingredient in chilli peppers, excites subpopulations of somatic and visceral sensory afferents (Holzer, 1991; Szolcsányi, 1993). Activation of these sensory neurons by capsaicin produces sensations of burning pain or irritation and activates protective reflexes and autonomic responses (Lundberg, 1993). In addition, a subset of capsaicin-activated sensory neurons release neuropeptides from their peripheral terminals, thereby eliciting neurogenic inflammation at the site of stimulation (Holzer, 1988; Holzer and Maggi, 1998). With high doses or prolonged exposure to capsaicin, neurons are functionally desensitized, exhibiting long-lasting loss of responsiveness to capsaicin and other stimuli (Szolcsányi, 1993; Winter et al., 1995). Such desensitization forms the basis for the use of capsaicin as an analgesic agent in the treatment of chronic pain conditions (Winter et al., 1995; Szallasi and Blumberg, 1996).

Recently, Caterina et al. (1997) reported the cloning of the vanilloid receptor subtype 1 (VR1), which binds capsaicin and other vanilloids. This receptor was described as a nonselective cation channel, with high $\mathrm{Ca}^{2+}$ permeability and sensitivity to noxious heat. Further characterization of its properties suggests

\footnotetext{
Received Aug. 26, 1998; revised Dec. 10, 1998; accepted Dec. 15, 1998.

This work was funded by the Medical Research Council of Great Britain. We thank Drs. D. O. Clary, T. Görcs, and Q. Yan for the provision of trkA, substance P, and RET antisera, respectively. We also thank Drs. S. B. McMahon for helpful suggestions concerning the project, P. J. Shortland for performing the spinal nerve sections, and V. R. King for help with statistical analyses.

Correspondence should be addressed to Dr. G. J. Michael, Neuroscience Section, Division of Biomedical Sciences, Queen Mary and Westfield College, Mile End Road, London E1 4NS, United Kingdom.

Copyright (C) 1999 Society for Neuroscience $\quad 0270-6474 / 99 / 191844-11 \$ 05.00 / 0$
}

that it is directly gated by heat and that its sensitivity is dramatically modulated by protons such that it is activated at room temperature under even moderately acidic conditions (Tominaga et al., 1998).

Physiological studies indicate that capsaicin-sensitive neurons are broadly defined as small cells with unmyelinated $(\mathrm{C})$ or thinly myelinated (A $\delta$ ) nerve fibers. Of these afferents, most capsaicinsensitive neurons are polymodal nociceptors, chemonociceptors, or warmth receptors. $\mathrm{C}$ - and $\mathrm{A} \delta$-fiber mechanoreceptors, D-hair receptors, and cold receptors are not sensitive (for review, see Holzer, 1991; Szolcsányi, 1993). Small DRG cells are heterogeneous in their neurochemical phenotype, central projections, and neurophysiological characteristics (Hunt et al., 1992), and no subclassification matches the characteristics of the capsaicinsensitive population (Holzer, 1991). Both major classes of small cells, the peptidergic class responsive to NGF and the Griffonia simplicifolia isolectin B4 (IB4)-binding class responsive to glial cell line-derived neurotrophic factor (GDNF) (Bennett et al., 1998; Snider and McMahon, 1998), contain capsaicin-sensitive (Nagy et al., 1981; Jancsó, 1992) and VR1-immunoreactive (Tominaga et al., 1998) cells. Furthermore, capsaicin-sensitive afferents have been shown to vary in sensitivity (Seno and Dray, 1991, 1993; Stucky et al., 1998). Semiquantitative analysis of in situ hybridization allows relative levels of mRNA in cells to be compared between treatment groups or cell populations (Priestley et al., 1991; Chesselet and Weiss-Wunder, 1994). We have analyzed VR1 expression in histochemically identified DRG subpopulations to determine whether there is differential expression of VR1 that might reflect varied sensitivities to capsaicin. 
NGF has been shown previously to regulate the sensitivity of a subpopulation of cultured DRG cells to capsaicin (Winter et al., 1988, 1993; Aguayo and White, 1992). We have therefore examined whether axotomy, which disturbs the supply of peripheral neurotrophic factors, affects VR1 expression. Because conflicting results have been reported for the expression of VR1 in nodose ganglion (Caterina et al., 1997; Helliwell et al., 1998; Tominaga et al., 1998), we have also examined this issue in more detail and particularly the coexpression of VR1 with neurotrophin receptors.

\section{MATERIALS AND METHODS}

Animals and surgical methods. A total of 16 adult male Wistar rats (150-250 gm body weight) were used for this study. Six of these animals underwent unilateral sciatic nerve sections, and four other animals had lumbar spinal nerve sections. Surgery was performed under pentobarbitone anesthesia (40 mg/kg, Sagatal; Rhône Mérieux Ltd., Hertfordshire, UK). For sciatic nerve sections, the nerve was exposed and ligated $20 \mathrm{~mm}$ distal to the obturator tendon before cutting it further distally. Spinal nerve sections were performed at the level of the L5-L6 vertebrae. The spinal nerve was cut $2-3 \mathrm{~mm}$ distal to the ganglion. All animals were anesthetized with sodium pentobarbital and perfused through the ascending aorta with saline, followed by fresh $4 \%$ paraformaldehyde in 0.1 $\mathrm{M}$ phosphate buffer, $\mathrm{pH}$ 7.4. Animals that had sciatic nerve sections were perfused 4, 7, and $14 \mathrm{~d}(n=4)$ after surgery. Animals that had spinal nerve section were perfused after $14 \mathrm{~d}$.

Tissue preparation. All tissues were prepared using histochemical methods described previously in detail (Michael and Priestley, 1996; Michael et al., 1997). Lumbar dorsal root, sympathetic, and nodose ganglia were removed, post-fixed for $2 \mathrm{hr}$ in the same fixative, and cryoprotected overnight in $15 \%$ sucrose in phosphate buffer. Tissues were frozen in OCT mounting medium (BDH Chemicals, Poole, UK) and sectioned on a cryostat at a thickness of $6 \mu \mathrm{m}$. The sections were thaw-mounted onto Superfrost Plus slides (BDH Chemicals).

Staining procedures. When using combined methodologies, indirect immunofluorescence and Griffonia simplicifolia isolectin B4 (IB4)binding histochemistry were performed before in situ hybridization. The following antisera, the staining characteristics and specificity of which have been reported previously, were used in immunohistochemistry: rabbit anti-trkA [1:4000 (Clary et al., 1994; Averill et al., 1995)]; sheep anti-calcitonin gene-related protein (CGRP) [1:600; Affiniti, Exeter, UK (Averill et al., 1995)]; mouse monoclonal anti-neurofilament [1:600, clone N52; Sigma, Poole, UK (Bennett et al., 1998)]; protein gene product 9.5 (PGP9.5) [1:2000; Ultraclone, Willows, UK (Wilson et al., 1988)]; rabbit anti-RET [1:500; gift from Dr. Q. Yan, Amgen Inc., Thousand Oaks, CA (Molliver et al., 1997)]; rabbit anti-somatostatin (1:1000; gift from Dr. T. Görcs, Semmelweis University, Budapest, Hungary); and rabbit antisubstance P (1:1000; gift from Dr. T. Görcs). Antibodies were diluted in antibody buffer containing $0.2 \%$ Triton $\mathrm{X}-100,0.1 \%$ sodium azide, 0.5 $\mathrm{mM}$ dithiothreitol, and $100 \mathrm{U} / \mathrm{ml} \mathrm{RNasin} \mathrm{ribonuclease} \mathrm{inhibitor} \mathrm{(Pro-}$ mega, Madison, WI) in diethylpyrocarbonate (DEPC)-treated PBS. IB4binding histochemistry was performed on sections being stained for trkA by adding $5 \mu \mathrm{g} / \mathrm{ml}$ biotinyl-IB4 (Sigma) to the primary antibody solution and supplementing to a final concentration of $0.1 \mathrm{~mm}$ with $\mathrm{CaCl}_{2}$, $\mathrm{MnCl}_{2}$, and $\mathrm{MgCl}_{2}$. Sections were incubated 40-48 hr at room temperature in the primary antibody solution, washed three times for $10 \mathrm{~min}$ each in DEPC PBS and incubated $4 \mathrm{hr}$ in the appropriate secondary antibodies linked to tetramethyl rhodamine isothiocyanate (TRITC) (1:200-1:400; Jackson ImmunoLaboratories, West Grove, PA) diluted in antibody buffer. IB4 binding was detected by including ExtrAvidin conjugated fluorescein isothiocyanate (FITC) (1:200; Sigma) in this incubation. Three final DEPC PBS washes were conducted before processing of the sections for in situ hybridization.

Our protocol for in situ hybridization of freshly cut or previously immunostained sections has been described in detail previously (Michael et al., 1997). After acetylation, dehydration, and delipidation pretreatment, mRNAs in sections were hybridized with specific oligonucleotide probes (Genosys Biotechnologies, Cambridge, UK). Two probe sequences were used, which were complimentary to the rat vanilloid receptor mRNA (Caterina et al., 1997) at bases 509-542 (TCCTGTCTCTGGGTCTTTGAACTCGCTGTCAGTC) and 2601-2634 (ACCCAAAGACCCCGCATTGATCCCTGCATAGTGT). BLAST sequence searches of the GenBank database failed to identify any known rat sequences other than VR1 to which these probes would be likely to hybridize using our reaction conditions. Oligonucleotide probes to trkA, trkB, and trkC were used in the analysis of the nodose ganglia and have been described previously (Michael et al., 1997). Radioactive probes were made by end-labeling the oligonucleotides with ${ }^{35}$ S-dATP (NEN, Hounslow, UK) using terminal deoxynucleotidyl transferase (Promega). Hybridization was performed overnight at $37^{\circ} \mathrm{C}$. After posthybridization washes and dehydration, slides were dipped in autoradiographic emulsion (Amersham, Arlington Heights, IL) and left for 3-6 weeks before development.

After development, sections that had only been labeled for mRNA were counterstained for Nissl substance using toluidine blue, dehydrated, and mounted from Histoclear II using Histomount (National Diagnostics, Hull, UK). Immunostained sections were mounted in PBS glycerol (1:3; containing 2.5\% 1,4-diazobicyclo-(2,2,2)-octane antifading agent; Sigma). Silver grains and fluorescence signals were visualized using epifluorescence microscopy, combined with epipolarized or dark-field illumination.

Controls for specificity of in situ hybridization included adding a 100 -fold excess of unlabeled oligonucleotide to the hybridization reactions, which effectively competed all specific binding of radiolabeled probe. The two different oligonucleotide probes to the VR1 mRNA sequence produced identical patterns of specific labeling in the dorsal root and nodose ganglia. In situ hybridization to sympathetic ganglion cells of the superior cervical ganglion, which are not sensitive to capsaicin (for review, see Holzer, 1991), was used as a negative control. Hybridization of dorsal root ganglion sections with the trk probes used in this study produce specific patterns of labeling (Michael et al., 1997) distinct to that obtained using the VR1 probe.

Imaging and quantitation. Sections were viewed on Leica (Wetzlar, Germany) epifluorescence microscopes using Y3 (TRITC), L4 (FITC), and polarization filter blocks and bright-field and/or dark-field illumination. In combined preparations that used a fluorescent stain to identify cell populations, labeling was assessed by switching between the FITC or TRITC filter blocks and epipolarized illumination. Photographs were taken using a Hamamatsu (Herrsching, Germany) C4742-95 digital camera and HiPic software to capture images.

After in situ hybridization, counts of profiles showing VR1 mRNA expression were performed using a criterion whereby profiles were identified as positively labeled if they had clustered silver grains over the cell body when visualized using epipolarized illumination. This criterion correlated well, with a criterion of positive labeling being the mean of the background density plus two times the SD of this density. This latter criterion was used for analysis of positively labeled profiles after image analysis, which was conducted using Visilog image analysis software (Noesis, Vélizy, France) as described previously (Michael et al., 1997). Using a $25 \times$ magnification objective, images were captured by a Grundig FA87 digital camera with integrating frame store. The cells of interest were outlined manually using a computer mouse, and the area occupied by silver grains within each cell and their average diameters were calculated. An ANOVA showed differences in relative silver grain labeling between various cell populations. Subsequently, pairwise comparisons were conducted with Fisher's LSD test to assess statistical significance between individual populations.

\section{RESULTS}

\section{Expression of VR1 mRNA is restricted to N52-negative cells in the dorsal root ganglion}

Two oligonucleotide probes, complimentary to different parts of the VR1 mRNA sequence, were used to examine VR1 expression in lumbar DRG cells and produced similar results. The more 5 '-directed probe produced significantly less nonspecific background, and therefore, detailed analyses were conducted using this probe.

Analysis of toluidine blue counterstained sections showed that many DRG cells possessed VR1 mRNA, as indicated by clusters of silver grains over the cells (Fig. $1 a-d$ ). Specific labeling above background was seen in $46.7 \pm 1.9 \%$ of the total cell profiles. Labeled cells were invariably small- to medium-sized.

We used the antibody N52 against the high molecular weight $(200 \mathrm{kDa})$ neurofilament protein subunit to label the large- 

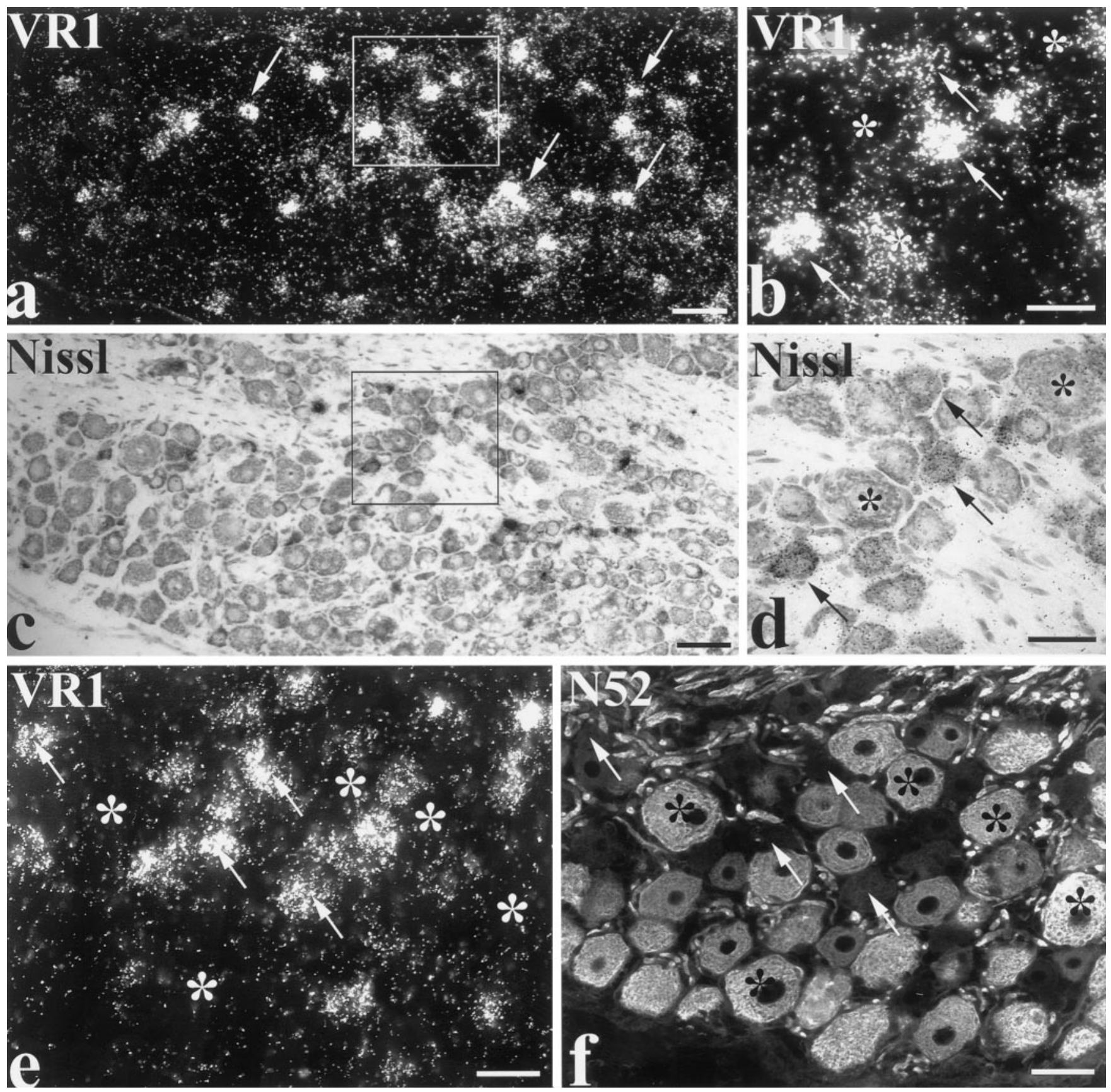

Figure 1. Expression of VR1 mRNA in the dorsal root ganglion is confined primarily to small- to medium-sized cells that do not stain for heavy chain neurofilament. In situ hybridization for VR1 mRNA $(a, b)$ with counterstaining of Nissl substance in cells with toluidine blue $(c, d)$. VR1 mRNA is expressed by only a subset of DRG cells $(a, c$, arrows). Higher magnification photomicrographs $(b, d)$ of the area indicated show that expression is restricted to small- to medium-sized cells, with the levels of VR1 mRNA differing considerably between cells (arrows). Large cells do not express this mRNA (asterisks). Combined in situ hybridization for VR1 mRNA $(e)$ and immunofluorescence for heavy chain neurofilament using antibody N52 ( $f$ ). Expression of VR1 mRNA is observed in many cells that are negative for neurofilament immunoreactivity $(e, f$, arrows). Almost all neurofilamentpositive cells are devoid of labeling for VR1 mRNA (e, f, asterisks). Scale bars: $a, c, 100 \mu \mathrm{m} ; b, d-f, 50 \mu \mathrm{m}$.

diameter DRG cell population. Very little overlap between expression of this marker and VR1 mRNA was observed (Fig. 1e,f). Of the N52-positive profiles, only $3.4 \pm 0.8 \%$ showed significant expression of VR1 mRNA. Almost all the profiles that were labeled for VR1 mRNA were N52-negative $(96.5 \pm 0.5 \%)$. Expression of VR1 mRNA was found in $83.2 \pm 1.8 \%$ of N52negative profiles. Because $54.5 \pm 2.6 \%$ of total profiles are N52negative, this would imply that $\sim 45 \%$ of total profiles have VR1
mRNA, in good agreement with our analysis of toluidine blue counterstained sections.

\section{VR1 mRNA is expressed by many cells in both the trkA and IB4 classes and exhibits wide-ranging relative levels}

For further analysis of the small DRG cells, we combined in situ hybridization for VR1 mRNA with trkA immunocytochemistry 

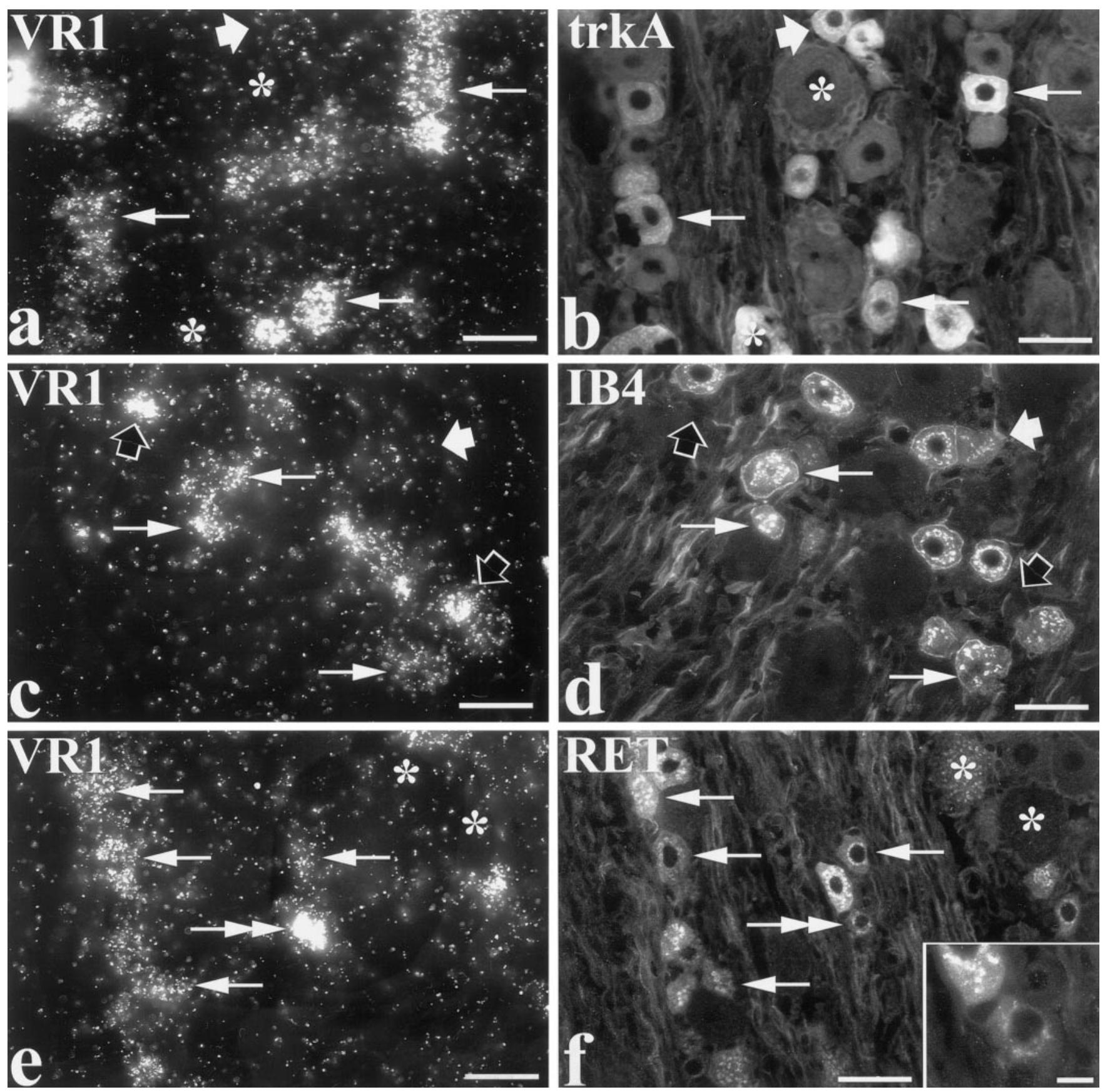

Figure 2. VR1 mRNA is expressed by both the NGF- and GDNF-responsive small cell populations. In situ hybridization for VR1 mRNA ( $a$, $c$, $e$ ) combined with fluorescence histochemistry $(b, d, f) . a, b$, trkA. Most small- to medium-sized trkA-immunoreactive cells express VR1 mRNA (thin arrows). A few small trkA cells (thick white arrows) and large-diameter cells (asterisks) have little or no detectable VR1 mRNA. $c, d$, IB4. As with the trkA subpopulation of small- to medium-sized cells, most IB4-labeled cells express VR1 (thin arrows). Some IB4 cells, however, do not possess levels of VR1 mRNA above background (thick white arrows). Some very small-diameter IB4-negative profiles have high levels of VR1 mRNA (thick black arrows). $e, f$, RET. Whereas small RET-positive cells are often labeled for VR1 mRNA (thin arrows), large RET-positive cells and other large cells do not express VR1 (asterisks). A very small-diameter RET-positive cell is shown that has very high levels of VR1 mRNA (double arrows and insert in $f$ ). Scale bars: $a-f, 50 \mu \mathrm{m}$; inset, $10 \mu \mathrm{m}$.

and IB4 binding. These triple-labeled preparations permitted us to examine VR1 expression in both classes, as well as in the minor overlapping population labeled by both markers. The majority of both trkA and IB4 cells express VR1 mRNA; however, not all cells in either of these classes were labeled (Fig. $2 a-d$ ). Labeling for VR1 mRNA above threshold levels was seen in $65.2 \pm 1.4 \%$ of trkA profiles and $74.9 \pm 1.5 \%$ of IB 4 profiles. In addition, there were differences in labeling intensity, and these were explored by image analysis.

Profile size distributions for the trkA and IB4 classes were plotted against the grain density of cellular labeling for VR1 mRNA (Fig. $3 a-c$ ). This method of data presentation revealed several trends. First, large trkA profiles with diameters above $\sim 40$ $\mu \mathrm{m}$ were not labeled for VR1 mRNA. Second, the small- and 

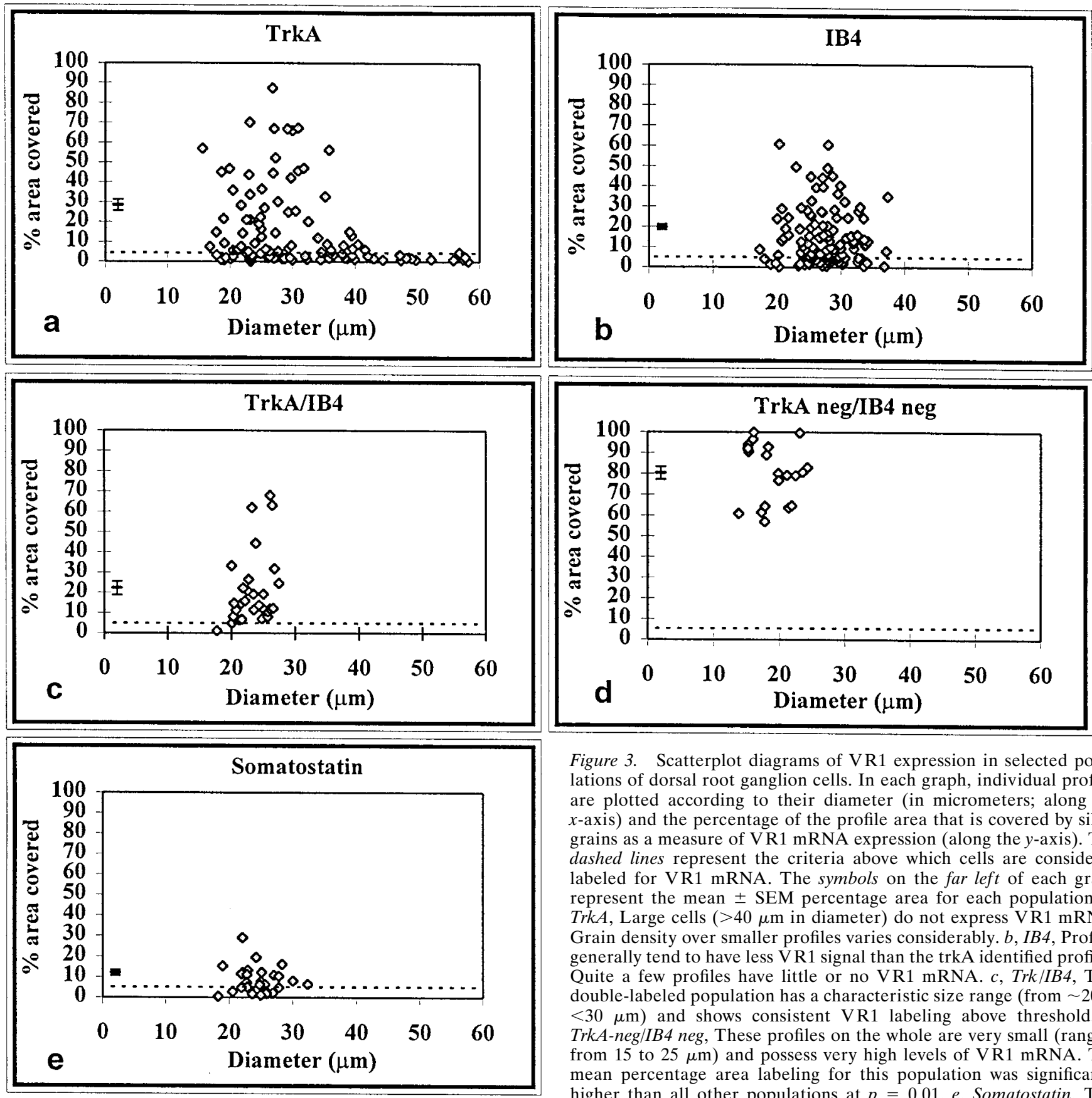

Figure 3. Scatterplot diagrams of VR1 expression in selected populations of dorsal root ganglion cells. In each graph, individual profiles are plotted according to their diameter (in micrometers; along the $x$-axis) and the percentage of the profile area that is covered by silver grains as a measure of VR1 mRNA expression (along the $y$-axis). The dashed lines represent the criteria above which cells are considered labeled for VR1 mRNA. The symbols on the far left of each graph represent the mean \pm SEM percentage area for each population. $a$, $\operatorname{Trk} A$, Large cells ( $>40 \mu \mathrm{m}$ in diameter) do not express VR1 mRNA. Grain density over smaller profiles varies considerably. $b, I B 4$, Profiles generally tend to have less VR1 signal than the trkA identified profiles. Quite a few profiles have little or no VR1 mRNA. $c$, Trk/IB4, This double-labeled population has a characteristic size range (from $\sim 20$ to $<30 \mu \mathrm{m})$ and shows consistent VR1 labeling above threshold. $d$, TrkA-neg/IB4 neg, These profiles on the whole are very small (ranging from 15 to $25 \mu \mathrm{m}$ ) and possess very high levels of VR1 mRNA. The mean percentage area labeling for this population was significantly higher than all other populations at $p=0.01$. e, Somatostatin, This subpopulation of IB4 cells exhibits characteristically low or beneath threshold levels of VR1 mRNA signal. The mean percentage area labeling was significantly lower than the trkA, trkA-negative/IB4-negative $(p=0.01)$, and trkA/IB4 $(p=0.05)$ populations.

medium-sized trkA or IB4 profiles had wide-ranging relative levels of the mRNA, with some profiles having high levels and others having little or none. Although some IB4 profiles showed heavy labeling, the majority were more lightly labeled. Third, the small but significant population of cells that label for both trkA and IB4 (representing $\sim 10-25 \%$ of trkA or IB4 cells) consistently expressed at least low relative levels of VR1 mRNA.

\section{A unique population of very small DRG cells has high relative levels of VR1 mRNA}

In all preparations examined, a few DRG cells had very high levels of VR1 mRNA. Figure 2 illustrates several examples of cell profiles covered with high levels of silver grains but not counter- stained with either trkA $(a, b)$ or IB4 $(c, d)$. Analysis of trkA and IB4 double-counterstained sections indicated that, although some trkA-positive cells were highly labeled, most of these heavily labeled profiles do not possess detectable levels of either marker. From a plot of size versus labeling density, such profiles can be seen to be among the smallest VR1-expressing cells (Fig. 3d) and have levels of labeling that are significantly higher than all the other populations studied (Fig. 3). These trkA-negative/IB4negative/VR1-positive profiles are not frequently found, comprising just over $1 \%$ (31 of 2495) of total profiles. To confirm that this small population of cells are in fact DRG neurons and not some other cell type, we counterstained sections with immuno- 

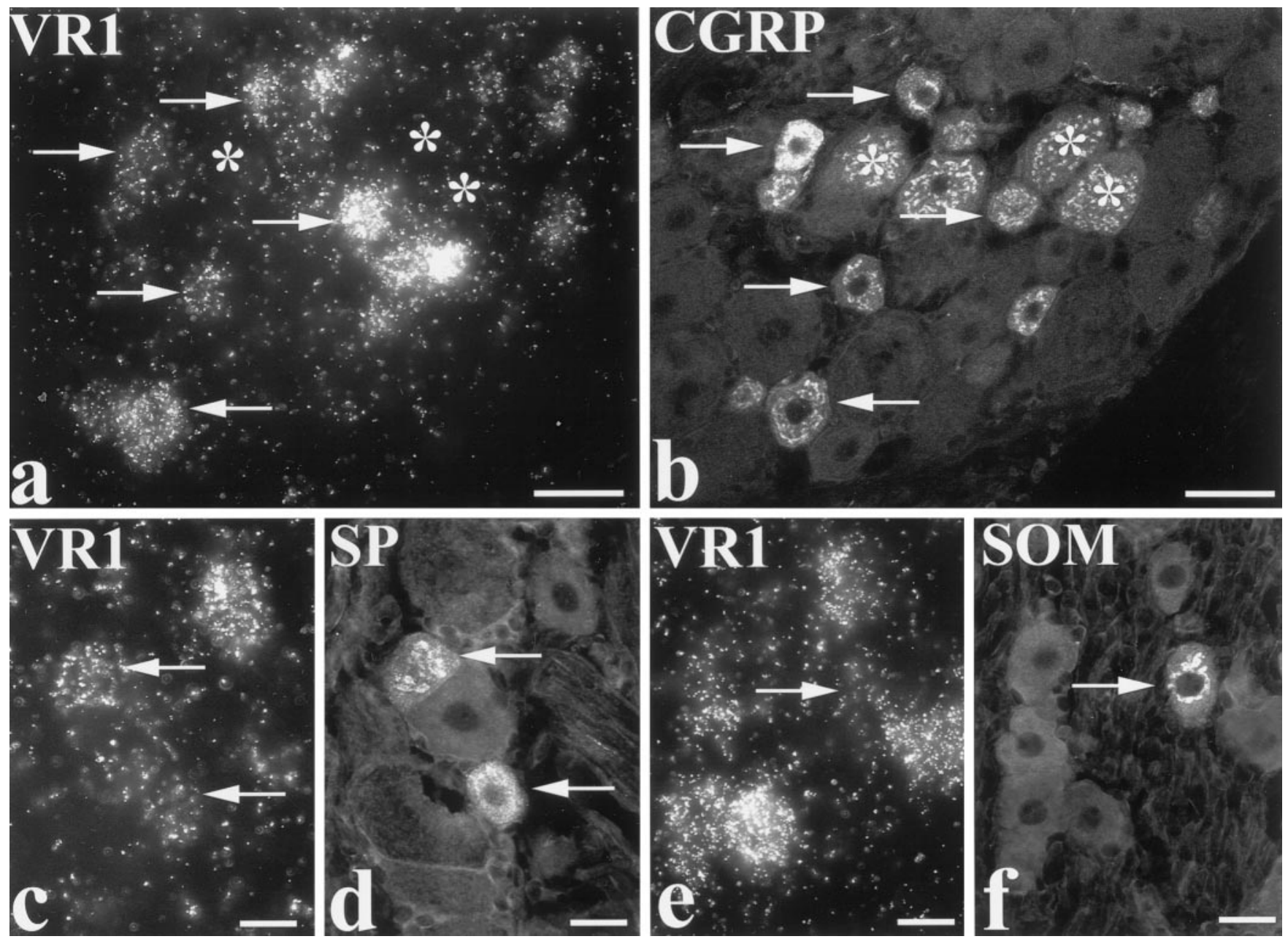

Figure 4. VR1 expression in identified subpopulations of dorsal root ganglion cells. In situ hybridization for VR1 mRNA was combined with immunofluorescence for the neuropeptides CGRP $(a, b)$, substance $\mathrm{P}(c, d)$, and somatostatin $(e, f)$. Thin white arrows identify cells that express VR1 mRNA and the particular neuropeptide. $a, b$, Small- to medium-sized CGRP cells express VR1 mRNA, with some cells containing relatively high levels of the message compared with others. Asterisks label large CGRP-immunoreactive cells that do not express VR1 mRNA. $c, d$, Similar to CGRP-positive cells, substance P-immunoreactive cells show variable levels of VR1 mRNA expression. $e, f$, The somatostatin cell identified in this photomicrograph expresses only low levels of VR1 mRNA. Scale bars: $a, b, 50 \mu \mathrm{m} ; c-f, 20 \mu \mathrm{m}$.

fluorescence for the neuron-specific marker PGP9.5. All cells labeled for VR1 mRNA in the dorsal root ganglion were counterstained for this marker (data not shown).

To further analyze these unusual cells, we examined expression of RET because this receptor tyrosine kinase has been shown previously to be expressed by many small DRG cells (Bennett et al., 1998). RET immunostaining, combined with in situ hybridization for VR1 mRNA, revealed that RET protein is present in many VR1-labeled cells, including most of the highly labeled cells. One such cell is shown in Figure 2, $e$ and $f$. Triple-labeled immunostaining for RET, trkA, and IB4 confirmed independently the existence of a small population of RET-positive cells in the lumbar DRG that do not label for trkA or IB4 (data not shown). VR1 labeling was confined to the small- and mediumsized RET profiles (Fig. $2 e, f$ ). Note that RET is also produced by a significant number of the large cells that do not express VR1 mRNA.

\section{VR1 mRNA and the expression of neuropeptides}

Sections labeled for VR1 mRNA and for peptides expressed by small DRG cells were analyzed to further characterize VR1 expression. Studies of coexpression with CGRP (Fig. 4a,b) and substance $\mathrm{P}$ (Fig. $4 c, d$ ), whose cell populations overlap extensively with the trkA population, indicated that most of these peptidergic neurons express VR1 mRNA. Large CGRP cells were invariably negative.

Double-labeling with somatostatin, which is localized exclusively to a small subset of the IB4-binding DRG cells, showed that many of these cells expressed VR1 mRNA. However, it was apparent that these cells were not labeled as heavily for the VR1 mRNA as many surrounding cells (Fig. 4e,f). This was confirmed by image analysis, which showed that these cells have significantly lower levels of labeling than most of the other populations (Fig. 3).

\section{The majority of neurons in the nodose ganglion express VR1 mRNA}

In situ hybridization of sections from the nodose ganglion showed relatively high levels of expression of VR1 mRNA (Fig. 5a-d). Analysis of emulsion-dipped sections counterstained with toluidine blue indicated that $81.6 \pm 1.0 \%$ of the nodose ganglion cell profiles label for VR1 mRNA. The labeling intensity varied 

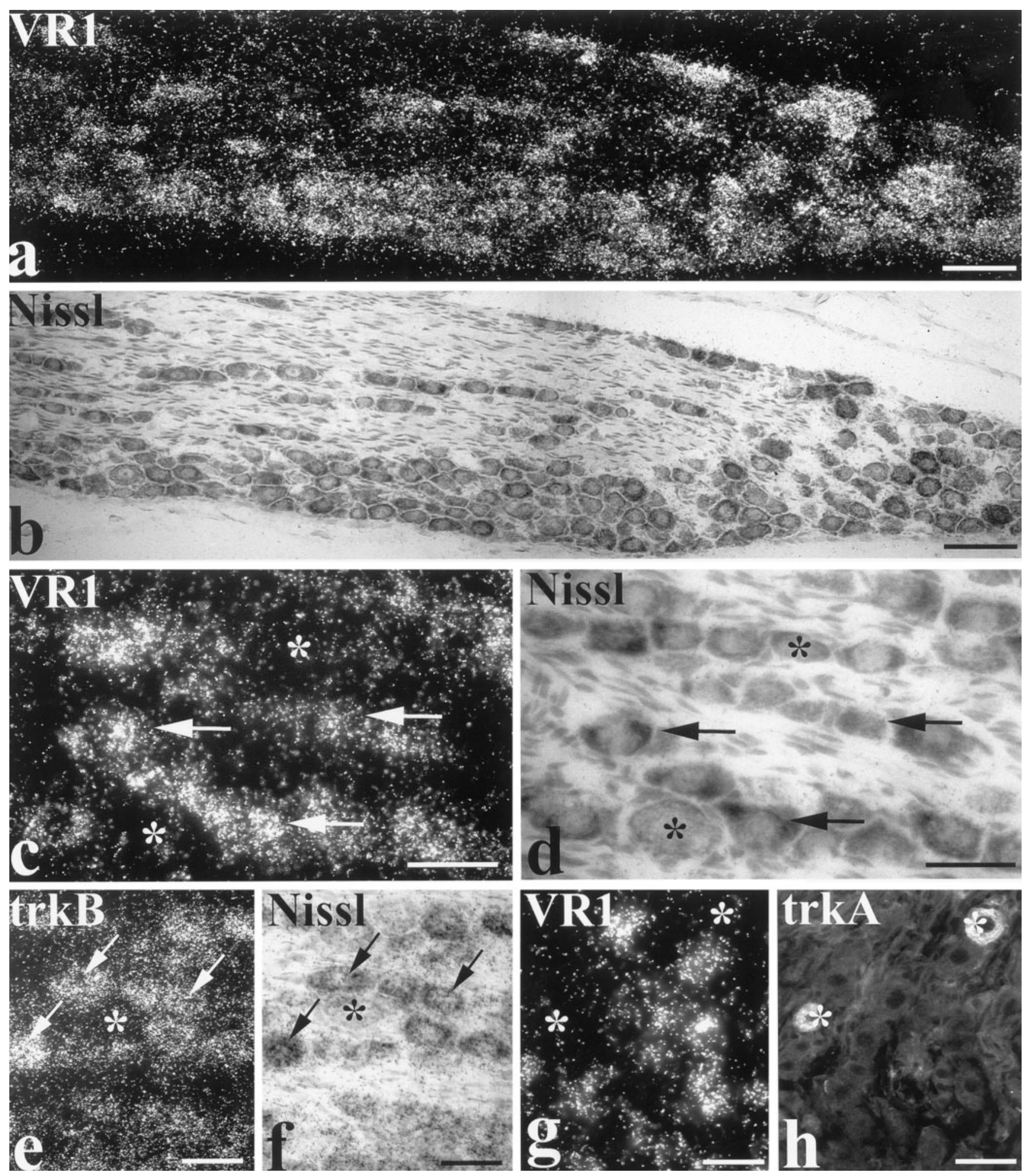

Figure 5. Expression of VR1 mRNA in the nodose ganglion. $a, b$, Moderate to high levels of VR1 mRNA were localized to most neurons of the nodose ganglion. $c, d$, At high magnification, labeled cells (arrows) show differing levels of the mRNA. Some cells are not labeled (asterisks).e, $f$, The mRNA for trkB is detected in most nodose ganglion cells. Arrows point to labeled cell profiles. Asterisks mark an unlabeled cell. $g, h$, VR1 mRNA is not detected in most nodose ganglion cells that express trkA protein (asterisks). Scale bars: $a, b, 100 \mu \mathrm{m} ; c-h, 50 \mu \mathrm{m}$.

considerably between cells as it did in the dorsal root ganglia. Unlabeled cells included a few large cells (Fig. $5 c, d$ ), which in double-labeled preparations were N52-immunoreactive (data not shown).
Semi-adjacent sections of nodose ganglia were processed for in situ hybridization of trk family receptors to compare their distributions with that of VR1. Signals for both trkA and trkC were only observed in small numbers of nodose ganglion cells; how- 
ever, trkB mRNA was detected in the majority of cells (Fig. $5 e, f$ ), indicating that many VR1 cells must express trkB. In contrast, combined VR1 in situ hybridization and trkA immunocytochemistry indicated that the few trkA-positive cells in the nodose ganglia have little or no detectable VR1 mRNA (Fig. $5 g, h$ ).

\section{VR1 levels in sensory neurons are decreased after axotomy}

To examine the regulation of VR1 mRNA in sensory neurons, in situ hybridization was performed on L4 ganglia after sciatic nerve section. Preliminary studies indicated that a reduction in the amount of VR1 mRNA occurs between 4 and $7 \mathrm{~d}$ after axotomy, and levels remain low at 2 weeks after lesion. Two weeks after axotomy, phenotypic changes in the small cell populations, including decreased expression of CGRP, trkA, and IB4 binding, are evident. The downregulation of CGRP after axotomy has been well characterized previously. Therefore, we examined more closely VR1 regulation in sections counterstained for this marker (Fig. $6 a-d)$ ). After sciatic nerve section, the number of CGRP-immunoreactive profiles in L4 ganglia was reduced from $35.7 \pm 3.8 \%$ of total on the contralateral uninjured side to $11.8 \pm$ $2.4 \%$ of total on the axotomized side. VR1 mRNA profiles were similarly decreased from $46.8 \pm 2.2$ to $15.7 \pm 2.3 \%$ of total. As in the uninjured ganglia, the VR1 mRNA-positive profiles that remained after axotomy are often CGRP-positive. The number of VR1 profiles in the uninjured contralateral L4 that were labeled for CGRP was $58.7 \pm 2.3 \%$ compared with $51.1 \pm 4.5 \%$ of VR1 profiles on the axotomized ganglia.

Spinal nerve section produced an almost complete loss of VR1 mRNA labeling in the axotomized ganglia, which was similar to the extent of loss found for CGRP, trkA, and IB4 binding. A comparison of in situ hybridization for VR1 mRNA and CGRP immunocytochemical counterstaining after spinal nerve section is shown in Figure $6 e, f$.

\section{DISCUSSION}

In this study, we show that expression of VR1 mRNA in DRG cells is restricted to neurofilament-negative cells but is present in both the peptide and nonpeptide subclasses. In addition, we show that there is considerable heterogeneity in the levels of VR1 mRNA expression, with a small subgroup of RETimmunoreactive DRG cells showing extremely high levels. In contrast, the level of VR1 expression in somatostatin cells is consistently low. Also, we show that VR1 is expressed by trkB, but not trkA, nodose ganglion cells and demonstrate that VR1 mRNA is downregulated in DRG cells after axotomy. These results, which are all novel, will be discussed in turn.

\section{VR1 expression in subpopulations of DRG cells}

VR1 mRNA has been shown previously to be present predominantly in small- and medium-sized cells (Caterina et al., 1997; Helliwell et al., 1998), but size alone is not adequate for classifying DRG cells (Lawson, 1992). Neurofilament expression has therefore become widely used as a DRG marker because it reliably distinguishes between cells with myelinated (neurofilamentpositive) and unmyelinated (neurofilament-negative) axons (Lawson, 1992). Our results strikingly show that VR1-expressing neurons are almost all N52-negative and hence belong to the small dark (B-type) population of DRG cells that give rise to unmyelinated $\mathrm{C}$ fibers. A few neurofilament-positive cells were seen to express VR1 and probably represent a population of capsaicinsensitive A $\delta$ nociceptors. This result is consistent with functional studies showing that capsaicin destroys primarily, but not exclusively, unmyelinated axons (Nagy et al., 1983).

To further classify VR1 expression in the B-type population, we have used markers that distinguish the two major subgroups that it comprises (Snider and McMahon, 1998). The majority of cells in both the trkA/peptide-expressing group and the IB4/ fluoride resistant acid phosphatase group expressed VR1 but with a different proportion of cells in each group. Some trkA cells are medium- or large-sized and are neurofilament-immunoreactive (18-28\% of all trkA profiles), so the expression of VR1 in trkA cells with unmyelinated axons will be higher than the $65 \%$ indicated by our total trkA counts and probably closer to $80-90 \%$. In contrast, the IB4 counts include trkA/IB4 double-labeled cells, and this subgroup expresses VR1. The expression of VR1 in the remaining "pure" IB4 cells will therefore be lower than the observed $75 \%$ and probably closer to $60 \%$ ( $\sim 25 \%$ of IB4 cells express trkA in this analysis). VR1 mRNA thus appears to be expressed by proportionally more trkA/peptide cells than IB4 cells. VR1 protein has been shown recently (Tominaga et al., 1998) to be expressed by $60-80 \%$ of IB4 cells and by most cells that contain substance $\mathrm{P}$, a peptide that is present in many small trkA/peptide cells (Lawson, 1992). Our results complement this study, showing that VR1 expression by unmyelinated trkA/peptide cells is a general characteristic of this group and not a particular feature of substance $\mathrm{P}$ cells.

Using image analysis, we were able to compare levels of VR1 expression by various DRG subgroups, and this revealed interesting differences. Small CGRP, substance P, and somatostatin cells all express VR1, but not all at high levels. Somatostatin cells had invariably low or below threshold levels of VR1 expression. This is consistent with data indicating that somatostatin cells are less sensitive to capsaicin than other DRG cells. Systemic capsaicin reduces levels of mRNA for substance P and CGRP by 50 and $30 \%$, respectively, but has no effect on somatostatin expression (Kashiba et al., 1997). In complete contrast to the somatostatin cells, we observed a few small DRG cells with very high levels of VR1 expression and unusual histochemical features. Negative for trkA or IB4 binding, these cells may be GDNF-sensitive because they express RET protein (Bennett et al., 1998). Although they comprise only a small number of cells, their very high levels of VR1 expression indicate that they are likely to have a unique sensory role.

The functional significance of the division of small DRG cells into two main subpopulations is unknown but has been the subject of much discussion (Hunt et al., 1992; Lynn, 1997; Snider and McMahon, 1998). Similarly, although neuropeptides such as substance $\mathrm{P}$ have been traditionally regarded as associated with nociceptors, their exact role and possible correlation with physiological subclasses is still poorly understood (Lynn, 1997). Our study, together with the recently detailed functional characterization of VR1 (Caterina et al., 1997; Tominaga et al., 1998), allows us to draw some tentative correlations between neurochemical and physiological subclasses. Thus, the patterns of VR1 expression indicate that most unmyelinated trkA cells and a subpopulation of IB4 cells are likely to mediate responses to noxious heat. Non-nociceptive $\mathrm{C}$ fibers, such as cooling and mechanoreceptive afferents, may be accounted for by the remaining IB4 cells. A striking feature of IB4 cells is that many selectively express the P2X ${ }_{3}$ ATP receptor (Bradbury et al., 1998; Vulchanova et al., 1998), a receptor which may be activated by ATP released after tissue damage (Cook et al., 1997). VR1 activation has also been proposed to be increased after tissue damage as a result of 

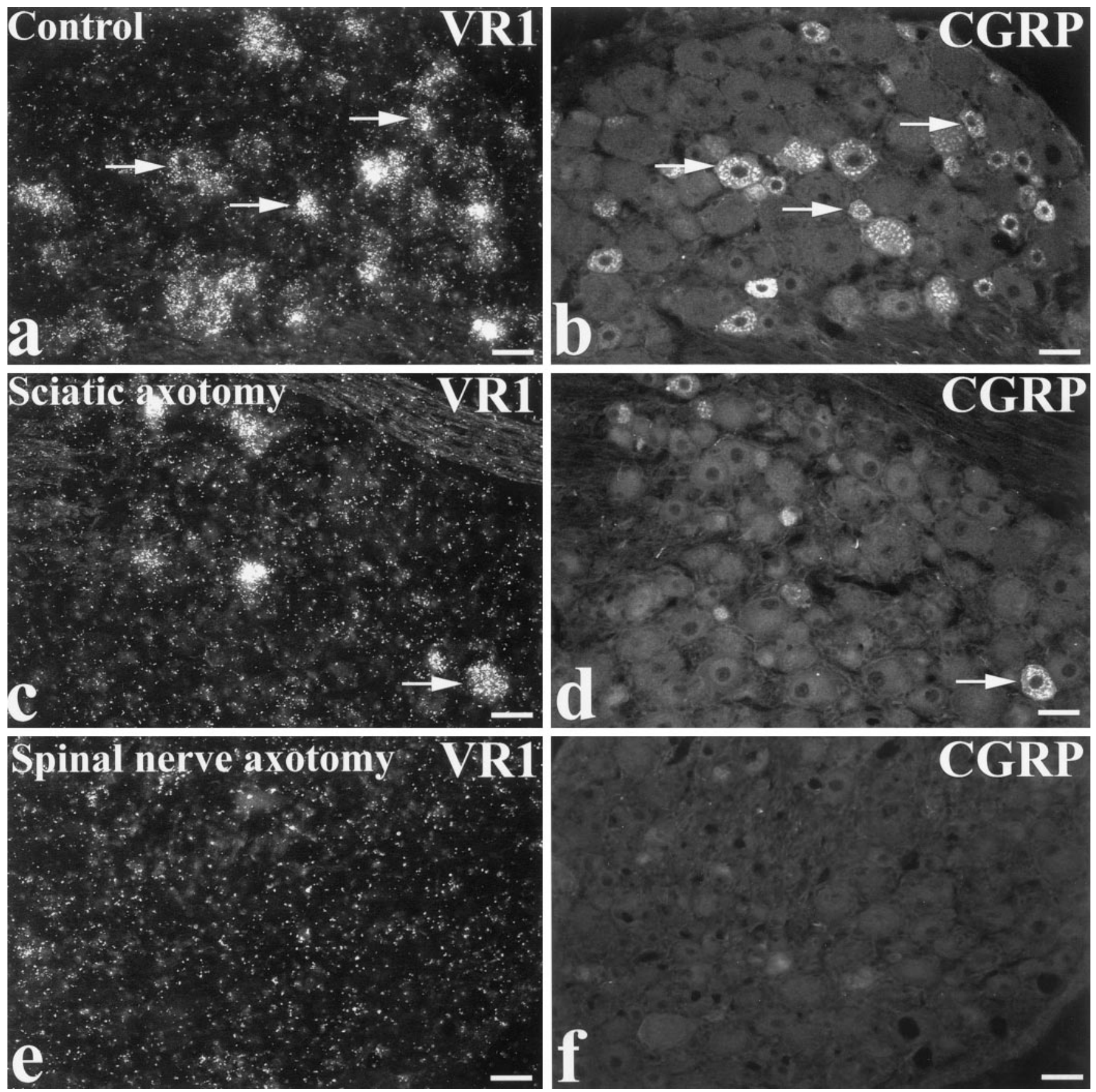

Figure 6. Expression of VR1 mRNA decreases in the DRG after axotomy. Combined in situ hybridization for VR1 mRNA and CGRP immunofluorescence was performed on sections from the contralateral control $(a, b)$, ipsilateral sciatic nerve-axotomized $(c, d)$, and spinal nerve-axotomized $(e$, $f$ ) dorsal root ganglia. In the control DRG, there is robust labeling for both VR1 mRNA and CGRP. Many cells coexpress both products $(a, b, a r r o w s)$. Ipsilateral to the sciatic nerve axotomy, there is a dramatic reduction in the number of cells labeled for VR1 or CGRP. Many of the remaining VR1-labeled cells are CGRP-immunoreactive. Arrows in $c$ and $d$ point to one example. After spinal nerve axotomy, both VR1 mRNA and CGRP expression is reduced throughout the ganglion. Scale bars, $50 \mu \mathrm{m}$.

modulatory effects of protons (Tominaga et al., 1998). It is not known to what extent the $\mathrm{P}_{2} \mathrm{X}_{3}$-expressing IB4 cells overlap with the VR1-expressing ones, but coexpression of $\mathrm{P}_{2} \mathrm{X}_{3}$ and VR1 is likely to endow IB4 cells with a unique signaling role after tissue injury.

Expression of VR1 in small substance P and CGRP cells is consistent with many studies showing that these peptides are likely to be present in nociceptors (Lawson, 1992). However, the low VR1 expression seen in somatostatin cells is surprising in the light of studies showing that noxious heat selectively releases somatostatin (Kuraishi et al., 1985; Morton et al., 1989). Our results may indicate that somatostatin cells express another type of thermoreceptor.

\section{VR1 expression in the nodose ganglion}

We show that VR1 mRNA is expressed by most cells of the nodose ganglia, confirming a recent result reported by Helliwell and colleagues (1998). Caterina et al. (1997) were unable to 
detect VR1 expression in the nodose, but this might have been because of a lack of sensitivity. Capsaicin-sensitive visceral afferents have been well characterized (Holzer, 1991), and systemic capsaicin causes degeneration of many thin-diameter nodose afferents (Ritter and Dinh, 1988). Capsaicin-sensitive visceral and somatic afferents appear similar in that both transmit primarily chemical and nociceptive signals and are primarily $\mathrm{C}$ fibers (Holzer, 1991). Our results show that nodose cells that lack VR1 include large neurofilament-immunoreactive cells. This is consistent with studies showing that low threshold tracheal A $\delta$ mechanoreceptors originating in the nodose ganglia are neurofilamentpositive and capsaicin-insensitive (Riccio et al., 1996).

Recently, Winter (1998) has shown that brain-derived neurotrophic factor (BDNF), but not NGF, regulates the capsaicin sensitivity of adult nodose ganglion cells in culture. There have been conflicting reports as to whether nodose cells express trkB (Wetmore and Olson, 1995; Zhuo and Helke, 1996). Our finding that most adult nodose ganglion cells express trkB confirms the work of Wetmore and Olson (1995), and because most of these cells coexpress VR1, it is possible that BDNF may regulate the capsaicin sensitivity of these neurons in vivo. The lack of coexpression of trkA with VR1 explains why NGF is unable to regulate capsaicin sensitivity in the nodose and contrasts with its effects on DRG cells.

\section{Axotomy downregulates VR1 expression}

Spinal nerve section, which axotomizes all cells in the contributing dorsal root ganglion, led to a complete loss of both CGRP and VR1 expression. In contrast, sciatic section, which leaves some cells intact, produced only a partial loss. It is therefore most likely that the downregulation in VR1 expression is a direct response by DRG cells to axotomy. This may represent a cellular reaction to the injury and/or be a response to changed availability of trophic factors (Aldskogius et al., 1992). Further experiments are required to distinguish between these possibilities. However, we have shown that VR1-expressing cells possess receptors for NGF (trkA) and/or GDNF (RET). It has been shown previously that IB4 cells selectively express GDNF receptors and that the axotomy-induced downregulation of various substances present in IB4 and trkA cells can be prevented by the appropriate exogenous factor (i.e., GDNF or NGF) (Bennett et al., 1998). The loss of VR1 expression after axotomy may therefore reflect loss of local or target-derived NGF or GDNF. Consistent with this interpretation, DRG cells cultured in the absence of NGF display a loss in capsaicin sensitivity, which can be reversed by NGF (Winter et al., 1988, 1993). Somewhat in contrast with our results, nerve section has been reported to not significantly affect DRG binding of the vanilloid analog resiniferatoxin (RTX) (FarkasSzallasi et al., 1996). This may indicate the presence of another subtype of vanilloid receptor, because Acs and colleagues (1996, 1997) have proposed that resiniferatoxin may act at a distinct RTX-selective vanilloid receptor. Whether another VR subtype is expressed concomitantly with VR1 and how vanilloid receptor expression is regulated in physiology and pathology deserve further investigation. One specific question that can be addressed is whether the thermal hyperalgesia associated with inflammation and increased tissue NGF levels is partly caused by an NGFmediated increase in VR1 expression. Control of vanilloid receptor expression in conditions of inflammation or other chronic pain states could provide a powerful new approach to pain treatment.

\section{REFERENCES}

Acs G, Biro T, Acs P, Modarres S, Blumberg PM (1997) Differential activation and desensitization of sensory neurons by resiniferatoxin. J Neurosci 17:5622-5628.

Acs G, Lee J, Marquez VE, Blumberg PM (1996) Distinct structureactivity relations for stimulation of ${ }^{45} \mathrm{Ca}$ uptake and for high-affinity binding in cultured rat dorsal root ganglion neurons and dorsal root ganglion membranes. Mol Brain Res 35:173-182.

Aguayo LG, White G (1992) Effects of nerve growth factor on TTXsensitivity and capsaicin-sensitivity in adult rat sensory neurons. Brain Res 570:61-67.

Aldskogius H, Arvidsson J, Grant G (1992) Axotomy-induced changes in primary sensory neurons. In: Sensory neurons. Diversity, development, and plasticity (Scott SA, ed), pp 363-383. New York: Oxford UP.

Averill S, McMahon SB, Clary DO, Reichardt LF, Priestley JV (1995) Immunocytochemical localization of trkA receptors in chemically identified subgroups of adult rat sensory neurons. Eur J Neurosci 7:1484-1494.

Bennett DLH, Michael GJ, Ramachandran N, Munson JB, Averill S, Yan Q, McMahon SB, Priestley JV (1998) A distinct subgroup of small DRG cells express GDNF receptor components and GDNF is protective for these neurons after nerve injury. J Neurosci 18:3059-3072.

Bradbury EJ, Burnstock G, McMahon SB (1998) The expression of $\mathrm{P}_{2} \mathrm{X}_{3}$ purinoreceptors in sensory neurons: effects of axotomy and glialderived neurotrophic factor. Mol Cell Neurosci 12:256-268.

Caterina MJ, Schumacher MA, Tominaga M, Rosen TA, Levine JD, Julius D (1997) The capsaicin receptor: a heat-activated ion channel in the pain pathway. Nature 389:816-824.

Chesselet M-F, Weiss-Wunder LT (1994) Quantification of in situ hybridization histochemistry. In: In situ hybridization in neurobiology (Eberwine JH, Valentino KL, Barchas JD, eds), pp 114-123. New York: Oxford UP.

Clary DO, Weskamp G, Austin LR, Reichardt LF (1994) TrkA crosslinking mimics neuronal responses to nerve growth factor. Mol Biol Cell 5:549-563.

Cook SP, Vulchanova L, Hargreaves KM, Elde R, McCleskey EW (1997) Distinct ATP receptors on pain-sensing and stretch-sensing neurons. Nature 387:505-508.

Farkas-Szallasi T, Bennett GJ, Blumberg PM, Hökfelt T, Lundberg JM, Szallasi A (1996) Vanilloid receptor loss is independent of the messenger plasticity that follows systemic resiniferatoxin administration. Brain Res 719:213-218.

Helliwell RJA, McLatchie LM, Clarke M, Winter J, Bevan S, McIntyre $\mathrm{P}$ (1998) Capsaicin sensitivity is associated with the expression of the vanilloid (capsaicin) receptor (VR1) mRNA in adult rat sensory ganglia. Neurosci Lett 250:177-180.

Holzer P (1988) Local effector functions of capsaicin-sensitive sensory nerve endings: involvement of tachykinins, calcitonin gene-related peptide and other neuropeptides. Neuroscience 24:739-768.

Holzer P (1991) Capsaicin: cellular targets, mechanisms of action, and selectivity for thin sensory neurons. Pharmacol Rev 43:143-201.

Holzer P, Maggi CA (1998) Dissociation of dorsal root ganglion neurons into afferent and efferent-like neurons. Neuroscience 86:389-398.

Hunt SP, Mantyh PW, Priestley JV (1992) The organization of biochemically characterized sensory neurons. In: Sensory neurons. Diversity, development, and plasticity (Scott SA, ed), pp 60-76. New York: Oxford UP.

Jancsó G (1992) Pathobiological reactions of C-fibre primary sensory neurons to peripheral nerve injury. Exp Physiol 77:405-431.

Kashiba H, Ueda Y, Senba E (1997) Systemic capsaicin in the adult rat differentially affects gene expression for neuropeptides and neurotrophin receptors in primary sensory neurons. Neuroscience 76:299-312.

Kuraishi Y, Hirota N, Sato Y, Hino Y, Satoh M, Takagi H (1985) Evidence that substance $\mathrm{P}$ and somatostatin transmit separate information related to pain in the spinal dorsal horn. Brain Res 325:294-298.

Lawson SN (1992) Morphological and biochemical cell types of sensory neurons. In: Sensory neurons. Diversity, development, and plasticity (Scott SA, ed), pp 27-59. New York: Oxford UP.

Lundberg JM (1993) Capsaicin-sensitive sensory nerves in the airways-implications for protective reflexes and disease. In: Capsaicin in the study of pain (Wood JN, ed), pp 219-237. London: Academic.

Lynn B (1997) Substance P and nociceptive afferent neurones. J Physiol (Lond) 505:1. 
Michael GJ, Priestley JV (1996) Combined immunocytochemistry and in situ hybridization. In: In situ hybridization techniques for the brain (Henderson Z, ed), pp 111-118. New York: Wiley.

Michael GJ, Averill S, Nitkunan A, Rattray M, Bennett DLH, Yan Q, Priestley JV (1997) Nerve growth factor treatment increases brainderived neurotrophic factor selectively in trkA-expressing dorsal root ganglion cells and in their central terminations within the spinal cord. J Neurosci 17:8476-8490.

Molliver DC, Wright DE, Leitner ML, Parsadanian AS, Doster K, Wen D, Yan Q, Snider WD (1997) IB4-binding DRG neurons switch from NGF to GDNF dependence in early postnatal life. Neuron 19:849-861.

Morton CR, Hutchison WD, Hendry IA, Duggan AW (1989) Somatostatin-evidence for a role in thermal nociception. Brain Res 488:89-96.

Nagy JI, Hunt SP, Iversen LL, Emson PC (1981) Biochemical and anatomical observations on the degeneration of peptide-containing primary afferent neurons after neonatal capsaicin. Neuroscience 6:1923-1934.

Nagy JI, Iversen LL, Goedert M, Chapman D, Hunt SP (1983) Dosedependant effect of capsaisin on primary sensory neurons in the neonatal rat. J Neurosci 3:399-406.

Priestley JV, Réthelyi M, Lund PK (1991) Semi-quantitative analysis of somatostatin mRNA distribution in the rat central nervous system using in situ hybridization. J Chem Neuroanat 4:131-153.

Riccio MM, Kummer W, Biglari B, Myers AC, Undem BJ (1996) Interganglionic segregation of distinct vagal afferent fiber phenotypes in guinea-pig airways. J Physiol (Lond) 496:521-530.

Ritter S, Dinh TT (1988) Capsaicin-induced neuronal degeneration: silver impregnation of cell bodies, axons, and terminals in the central nervous system of the adult rat. J Comp Neurol 271:79-90.

Seno N, Dray A (1991) Selective activation by capsaicin of polymodal nociceptors in the rat hind paw skin saphenous nerve in vitro and antagonism by capsazepine. J Physiol (Lond) 438:P120.

Seno N, Dray A (1993) Capsaicin-induced activation of fine afferent fibers from rat skin in vitro. Neuroscience 55:563-569.

Snider WD, McMahon SB (1998) Tackling pain at the source: new ideas about nociceptors. Neuron 20:629-632.

Stucky CL, Abrahams LG, Seybold VS (1998) Bradykinin increases the proportion of neonatal rat dorsal root ganglion neurons that respond to capsaicin and protons. Neuroscience 84:1257-1265.

Szallasi A, Blumberg PM (1996) Vanilloid receptors: new insights enhance potential as a therapeutic target. Pain 68:195-208.

Szolcsányi J (1993) Actions of capsaicin on sensory receptors. In: Capsaicin in the study of pain (Wood JN, ed), pp 1-26. London: Academic.

Tominaga M, Caterina MJ, Malmberg AB, Rosen TA, Gilbert H, Skinner K, Raumann BE, Basbaum AI, Julius D (1998) The cloned capsaicin receptor integrates multiple pain-producing stimuli. Neuron 21:531-543.

Vulchanova L, Riedl MS, Shuster SJ, Stone LS, Hargreaves KM, Buell G, Surprenant A, North RA, Elde R (1998) P2X 3 is expressed by DRG neurons that terminate in inner lamina II. Eur $\mathrm{J}$ Neurosci 10:3470-3478.

Wetmore C, Olson L (1995) Neuronal and nonneuronal expression of neurotrophins and their receptors in sensory and sympathetic ganglia suggest new intercellular trophic interactions. J Comp Neurol 353:143-159.

Wilson PO, Barber PC, Hamid QA, Power BF, Dhillon AP, Rode J, Day IN, Thompson RJ, Polak JM (1988) The immunolocalization of protein gene product 9.5 using rabbit polyclonal and mouse monoclonal antibodies. Br J Exp Pathol 69:91-104.

Winter J (1998) Brain-derived neurotrophic factor, but not nerve growth factor, regulates capsaicin sensitivity of rat vagal ganglion neurones. Neurosci Lett 241:21-24.

Winter J, Forbes CA, Sternberg J, Lindsay RM (1988) Nerve growth factor (NGF) regulates adult rat cultured dorsal root ganglion neuron responses to the excitotoxin capsaicin. Neuron 1:973-981.

Winter J, Walpole CSJ, Bevan S, James IF (1993) Characterization of resiniferatoxin binding sites on sensory neurons: co-regulation of resiniferatoxin binding and capsaicin sensitivity in adult rat dorsal root ganglia. Neuroscience 57:747-757.

Winter J, Bevan S, Campbell EA (1995) Capsaicin and pain mechanisms. Br J Anaesth 75:157-168.

Zhuo H, Helke CJ (1996) Presence and localization of neurotrophin receptor tyrosine kinase (TrkA, TrkB, TrkC) messenger RNAs in visceral afferent neurons of the nodose and petrosal ganglia. Mol Brain Res 38:63-70. 